\title{
A Duração como Correlato Acústico do Acento de Palaura no Português Brasileiro e no Espanhol: desafios para o ensino de suprassegmentais e preparação de material didático
}

\author{
The Duration as an Acoustic Correlate of Word Stress in \\ Brazilian Portuguese ANd SPANISH: CHALLENGES FOR TEACHING \\ SUPRASEGMENTAL AND PREPARATION OF TEACHING MATERIALS
}

Letânia Patricio FERREIRA*

Resumo: O presente artigo segue a linha da linguística contrastiva e tem o objetivo de analisar o mecanismo de contraste entre sílabas tônicas e átonas, no Português Brasileiro (PB) e no Espanhol, no que diz respeito à duração, e de discutir as implicações dos resultados obtidos para a construção de material didático. Resultados indicam que a duração opera de forma mais constante e sistemática como correlato de proeminência lexical no Português. Por aportar uma análise contrastiva entre as duas línguas, esse trabalho fornece informações detalhadas e úteis sobre suprassegmentais. O uso destas informações, tanto de forma implícita como explícita, pode ser de grande benefício para alunos e professores que trabalham com ambas as línguas. A inclusão de tais informações na preparação de material didático pode potencializar o aprendizado e facilitar o uso de suprassegmentais na L2.

Palavras-chave: Duração. Suprassegmentais. Material didático.

Abstract: This paper follows the line of contrastive linguistics and aims to analyze the contrast mechanism that differentiates stressed from unstressed

* Possui Doutorado em Linguística pela University of Illinois at Urbana-Champaign. Mestre em Línguas Latinas pela University of Georgia, Athens. No presente, atua como pesquisadora na Universidade Federal de Pernambuco, com bolsa de Pós-Doutorado pela FACEPE/CNPq. Contato: letaniaferreira@gmail.com. 
syllables, in Brazilian Portuguesa (BP) and Spanish, in relation to duration. The paper aims as well to discuss how of results can be useful in the construction of teaching materials. Results indicate that duration operates at a more consistent and systematic way as correlate of lexical prominence in Portuguese. By presenting a contrastive analysis between the two languages, this work provides detailed and useful information about suprasegmentals. This contribution can be used both implicitly and explicitly to benefit students and teachers working with both of these languages. Including such information in the elaboration of teaching materials may provide opportunities to enhance learning and facilitate the use of suprasegmentals in L2.

Key words: Duration. Suprasegmentals. Teaching material.

\section{Introdução}

Entre outros importantes aspectos no processo de ensino-aprendizagem de línguas estrangeiras, o ensino da pronunciação tem passado por diferentes abordagens e posições de destaque. Em cada uma das diferentes abordagens metodológicas, distintos papéis e níveis de relevância foram atribuídos ao seu ensino. Um dos grandes desafios no ensino da pronunciação tem sido a abordagem dos aspectos suprassegmentais nos currículos de língua. Embora exista evidência científica dos benefícios que tal instrução pode trazer à inteligibilidade, o ensino de suprassegmentais não é priorizado nos programas de língua e na composição de material didático comercial. No que diz respeito especificamente ao ensino de Espanhol a falantes de Português Brasileiro (PB), além da semelhança entre ambos os idiomas, a falta de descrição adequada das diferenças entre os aspectos suprassegmentais dessas línguas se estabelece como uma lacuna que fortalece as barreiras para a inclusão de suprassegmentais tanto na sala de aula como no material didático. O presente trabalho apresenta dados empíricos sobre diferenças suprassegmentais entre o PB e o Espanhol. Esse conhecimento pode ser usado como instrumento para professores e alunos de Espanhol no Brasil, ou no ensino-aprendizagem de Português para nativos de Espanhol, promovendo, assim, maior inteligibilidade e abrindo portas para a inclusão dos aspectos suprassegmentais no ensino da pronunciação e na construção do material didático.

Neste artigo, parte-se do princípio de que o ramo da Linguística Contrastiva se tornou uma área indispensável de apoio à Linguística Aplicada 
(NICKEL; WAGNER 2009), por permitir a compreensão em detalhes dos fenômenos linguísticos que contrastam entre dois idiomas, o que possibilitaria a construção de ferramentas específicas que auxiliam o aprendizado de pontos particulares de divergência entre línguas.

Diante disso, propusemo-nos a analisar o funcionamento sistemático da duração, um importante correlato acústico para a expressão do acento de palavra e do ritmo, tanto no PB quanto no Espanhol. No presente trabalho, são expostos os resultados de um estudo acústico que aponta diferenças entre as línguas nos padrões de duração de sílabas tônicas e átonas. Com base nos resultados desse estudo, discute-se a relevância dos achados para o ensino de Espanhol para falantes de PB e apresentam-se sugestões de atividades que favorecem a habilidade de reconhecer e produzir material linguístico com base nesse correlato específico. A compreensão sistemática de como a duração funciona nesses idiomas permitirá maior esclarecimento para professores e alunos sobre o funcionamento dos traços suprassegmentais dessas línguas. Espera-se que essa informação contribua para a elaboração de um material didático que seja cada vez mais relevante e enriquecido. Advoga-se a favor da criação de material didático que ofereça instruções explícitas e implícitas sobre o contrataste entre essas línguas, possibilitando a prática de suprassegmentais e oferecendo oportunidades para que os falantes do Português, ao estudar Espanhol, desenvolvam ainda mais suas habilidades linguísticas.

A seção 1 desse artigo apresenta uma discussão sobre a relevância do ensino da pronunciação e dos aspectos suprassegmentais. A seção 2 apresenta o estudo. A subseção 2.1 oferece uma revisão bibliográfica do que se sabe sobre a duração como correlato acústico do acento lexical em PB e em Espanhol. A subseção 2.2 expõe a metodologia utilizada no estudo. $\mathrm{Na}$ subseção 2.3, são descritos os resultados do estudo. A subseção 2.4 apresenta a discussão dos resultados. A seção 3 aborda as implicações do estudo para a construção do material didático e a subseção 3.1 dá exemplo de atividades que podem facilitar a o ensino-aprendizagem dos resultados relevantes. As conclusões são apresentadas na seção seguinte.

\section{O Ensino de Pronunciação e os Suprassegmentais}

A grande similaridade entre o Espanhol e o Português inicialmente ajuda na inteligibilidade que os falantes monolíngues desses idiomas apresentam com relação à outra língua em situações de aprendizado. Para falantes de 
uma dessas línguas que estão aprendendo a outra, a transferência de conhecimento da língua materna (L1) poderá, de forma positiva, possibilitar que o desempenho de habilidades orais e escritas dos alunos chegue a um nível pós-elementar ainda nas primeiras semanas de instrução formal (CARVALHO, 2002). Partindo-se da larga definição proposta por Grosjean e Li (2013), segundo a qual o bilinguismo é o uso de duas ou mais línguas independente do nível linguístico que se possua em uma delas -, falantes de um desses idiomas podem, então, obter a habilidade bilíngue com rápida instrução formal. Essa facilidade inicial de aprendizagem traz a ameaça de que o aluno nativo de uma dessas línguas se sinta demasiado seguro com o uso das ferramentas linguísticas disponíveis na sua L1 ao expressar ideias na língua-alvo (L2). Dessa forma, a habilidade de poder reciclar grande parte de seu conhecimento de L1 para L2 se transforma em um problema, tendo em vista que a transferência linguística também pode acarretar consequências negativas, como, por exemplo, o risco de fossilização. Para Fialho (2006), a semelhança entre essas línguas causa a grande ameaça de que o falante de Português termine não por adquirir proficiência em língua espanhola ou que o nativo de Espanhol não alcance tal objetivo na língua portuguesa, e sim que esses falantes/alunos terminem por manter seu nível de fala na interlíngua ${ }^{1}$.

Não se quer, com isso, dizer que a interlíngua se compõe de um plano estático. Para nós, ela está em constante processo de reorganização, pois, como explica Ortega (2009), a interlíngua é um sistema linguístico construído por todo aprendiz de forma singular e que reflete cada dado momento de desenvolvimento no aprendizado linguístico. Cabe advertir, porém, que a similaridade entre essas línguas tem sido constantemente descrita por autores como um desafio para o aprendizado (CARMOLINGA, 1997; CONTERAS, 1998; CARVALHO, 2002 e FIALHO, 2006, entre outros). De forma geral, a literatura reporta que, embora em estágios iniciais de aprendizagem a proximidade entre o Português e o Espanhol facilite a tarefa de comunicação na outra língua, a grande semelhança entre estes dois idiomas pode prejudicar o aprendizado em estágios mais avançados.

É importante reconhecer, ainda, que diferentes aprendizes possuem metas diversas quanto às suas habilidades comunicativas. Alguns estão mais

${ }^{1}$ Fase obrigatória da aprendizagem linguística, a interlíngua é definida como um sistema linguístico interiorizado que difere tanto da língua materna como da língua-alvo (SELINKER, 2009). 
preocupados em adquirir a habilidade de comunicação oral, outros estão contentes em poder ler e escrever em língua estrangeira. Seja qual for o objetivo final do aluno, opina-se que é tarefa do professor incentivar o aprendiz no caminho de constante progresso. O problema parece ser que, enquanto existe um consenso sobre a importância da intervenção do professor no processo de desenvolvimento de algumas habilidades linguística dos alunos (como a escrita, por exemplo), outras partes do processo de aprendizagem de uma língua estrangeira nem sempre são tidas como áreas que pedem intervenção direta do instrutor. $\mathrm{Na}$ verdade, alguns autores inclusive argumentam que o estudo da pronunciação tem sido marginalizado no campo da Linguística Aplicada (DERWING; MUNRO, 2005).

Nos estudos referentes à pronunciação, vê-se que a especulação de que seria impossível adquirir um acento nativo em língua estrangeira levou à redução ou mesmo à eliminação completa do ensino de pronunciação em alguns programas de ensino (GILAKJANI, 2012). Alguns professores não intervêm na pronunciação dos alunos, seguindo o princípio de que os estudantes aprendem a pronúncia adequada apenas pelo contato com o input (AKERBERGUE, 2011). Outras linhas de raciocínio defendem que o ensino da pronunciação é imprescindível e que deve ocorrer não apenas em nível fonético, mas também em nível fonológico.

De forma ainda mais específica, alguns teóricos afirmam que cabe ao professor prover aos estudantes instrumentos que aumentem sua autonomia e facilitem a inteligibilidade. Tome-se como exemplo o ensino de técnicas que ajudem com a coarticulação de sons ou com o uso de suprassegmentais: o acento lexical, o ritmo e a entoação (ESLING; WONG, 1983; CHELA-FLORES, 2003; HAHN, 2004 e AKERBERGUE, 2011, entre outros). Daí a importância de enfatizar a inclusão dos suprassegmentais na agenda do ensino-aprendizagem de línguas estrangeiras. Os falantes que recebem instruções realçando as características suprassegmentais, de acordo com Chela-Flores (2003), conseguem transferir seu conhecimento para a produção espontânea mais efetivamente do que os falantes que receberam apenas instruções segmentais.

Autora de um dos poucos trabalhos que, ao comparar as características suprassegmentais do Português e do Espanhol, enfatiza implicações para o ensino-aprendizagem de uma dessas línguas por falantes nativos da outra, Akerbergue (2011) explica que o enraizamento dos suprassegmentais adquiridos na L1 de um indivíduo causa marca notável de acento estrangeiro 
na L2. A relevância do ensino de suprassegmentais, porém, vai bem além da preocupação com a marca do acento estrangeiro. Akerbergue (2011), que examinou os aspectos relacionados ao uso/aprendizado da entonação, verificou que a falta de reconhecimento adequado dos padrões entoacionais pode acarretar importantes erros de interpretação. Alguns participantes em seu estudo demonstraram, por exemplo, dificuldade em diferenciar perguntas de respostas na outra língua. De forma mais alarmante, seus resultados mostram ainda que o tempo de estudo de língua estrangeira não parece ter auxiliado o desempenho dos alunos. Estudantes de níveis linguísticos mais avançados não apresentaram melhor performance no reconhecimento de padrões entoacionais, o que pode ser resultado da falta de instrução específica sobre o tema. Diante de tais resultados, Akerbergue (2011) fala da necessidade de sensibilizar os alunos de língua estrangeira para funções suprassegmentais, como a entonação e o ritmo, através de atividades variadas e de exercícios de discriminação, com o intuito de favorecer a inteligibilidade.

Para além do ritmo e entonação, a inteligibilidade também está pautada em outros aspectos suprassegmentais, como é o caso do acento lexical, por exemplo. Estudos mostram que, quando expostos ao uso correto do acento de palavra, ouvintes tendem a processar o discurso mais facilmente. Além disso, a exposição ao uso correto do acento lexical permite que os ouvintes retenham maior quantidade de informação e tenham uma melhor impressão sobre os falantes (HAHN, 2004).

Conclui-se, então, que a relevância dos suprassegmentais para o ensino de línguas vai além da diminuição do acento estrangeiro, pois pode sim implicar na compreensão e, de forma positiva, promover a inteligibilidade. A duração, que impacta tanto o acento lexical como o ritmo linguístico, é um correlato acústico de grande importância para o estudo dos suprassegmentais. Tendo esse cenário como motivação, o objetivo deste trabalho é analisar o mecanismo de contraste entre sílabas tônicas e átonas, no PB e no Espanhol, no que diz respeito à duração, e discutir as implicações dos resultados obtidos para a construção de material didático. 


\section{Correlatos Acústicos do Acento de Palavra no Espanhol e no PB e o Papel da Duração}

\subsection{Correlatos acústicos do acento lexical}

Vários estudos mostram que a duração é um correlato acústico importante para a expressão do acento de palavra tanto no Português como no Espanhol. Major (1992), por exemplo, aponta a duração, a frequência fundamental (F0) e a intensidade como importantes correlatos acústicos do acento de palavra no PB. Embora grande parte da literatura que examina os parâmetros acústicos do acento de palavra mencione estes três correlatos nos estudos de algumas línguas e dialetos, serão notados também a inclusão da qualidade vocálica e do spectral tilt na lista dos parâmetros mais relevantes na tentativa de quantificar a presença do acento lexical. Tendo em vista que cada língua demonstra um determinado comportamento específico, deve-se perceber ainda que esses diferentes parâmetros acústicos se organizam de forma diversa dentro de uma escala hierárquica intrínseca a cada língua, segundo sua capacidade de expressar de maneira confiável a presença ou ausência do acento lexical.

A decisão sobre qual seria o principal correlato acústico do acento de palavra em cada uma das línguas do mundo não tem se mostrado unânime; observe-se que, em 1972, Câmara apontava o F0 como principal parâmetro acústico do acento lexical no PB. É importante ressaltar, porém, que as tecnologias criadas na última década do século $\mathrm{XX}$, assim como na primeira década do século XXI, propiciaram-nos uma nova perspectiva de análise, trazendo maior disponibilidade e simplicidade operacional dos instrumentos que permitem a avaliação acústica dos sons. Esses adventos tecnológicos fazem com que os estudos recentes sejam cada vez mais específicos e confiáveis. Ficará claro, mais tarde, que a duração, e não o F0, é o mais confiável dos parâmetros acentuais no PB. Esses resultados foram apresentados por Major (1992), e novos estudos acústicos, como Massini (1992) e Ferreira (2008), trazem confirmação do fato.

É importante lembrar que, mesmo sem tais instrumentos, Câmara (1972) conseguiu perceber que a proeminência de uma sílaba átona em PB depende da posição por ela ocupada dentro de uma palavra. Ele observou que as sílabas pré-tônicas são normalmente mais fortes que as pós-tônicas, resultados que foram confirmados por Massini (1992). Nota-se, também, 
que outros fatores fonológicos, como a influência do acento de frase, irão alterar o comportamento das sílabas acentuadas. Barbosa (2002) observa que, quando a sílaba tônica também recebe um acento frasal, a duração do ataque silábico aumentará mais que a duração da rima. De outra forma, sílabas que não recebem o acento de frase, mas apenas o acento lexical, sofrerão um aumento uniforme na duração de ambas, vogais e consoantes.

Historicamente, também há divergências na hierarquização dos correlatos do acento de palavra em Espanhol. Para Navarro Tomás (1926), a intensidade seria o mais relevante parâmetro do acento lexical nessa língua. Gili Gaya (1971), por sua vez, aponta a F0 como o principal indicador de proeminência acentual em palavras do Espanhol. Sem entrar em detalhes sobre a posição hierárquica ocupada por qualquer dos indicadores acentuais, Quilis (1993) simplesmente menciona que F0, duração e intensidade são os parâmetros acústicos que permitem identificar o acento de palavra neste idioma. Mais recentemente, Ortega-Llebaria (2006) separa os correlatos do acento de palavra dos correlatos do acento de frase. Ela observa que, em declarativas, F0 é um correlato de proeminência lexical altamente significativo. Em estudo posterior, Ortega-Llebaria e Prieto (2007) ampliam o número de correlatos acústicos do acento de palavra a serem analisados, acrescentando a avaliação da qualidade vocálica e do spectral tilt. As autoras concluíram que, em declarativas, nem a duração e nem a qualidade vocálica provaram ser correlatos significativos do acento lexical no idioma Espanhol, embora seja um correlato muito importante na percepção do acento de palavra em contextos onde se neutralizam os contrastes tonais, como nas frases parentéticas. Em trabalhos mais recentes, Ortega-Llebaria, Hong e Fan (2013) demonstram que, embora as diferenças de duração entre sílabas tônicas e átonas em Espanhol sejam, em general, pequenas, os falantes nativos desta língua percebem melhor estas diferenças do que falantes que a aprenderam como segunda língua.

\subsection{Metodologia}

Para verificar o funcionamento do mecanismo de contraste em ambas as línguas, foi realizada uma análise da duração como correlato acústico do acento de palavra no PB e no Espanhol. Para isso, mediu-se a duração de determinadas sílabas em posição átona para comparar com os valores obtidos em sílabas compostas pelos mesmos segmentos em posição tônica. 
Escolheu-se trabalhar com frases declarativas neutras que são comuns na linguagem natural. A distinção entre sílabas pré e pós-tônicas discutida na literatura foi levada em consideração para o presente estudo e, a fim de simplificar os resultados, apenas sílabas pré-tônicas são observadas no experimento proposto. Seguiu-se o modelo experimental utilizado por Massini (1992) e decidiu-se observar a duração da sílaba completa e não apenas a variação da duração vocálica. Para evitar a possível interferência do acento frasal descrito por Barbosa (1996), todas as palavras avaliadas no presente experimento foram obtidas na mesma posição da frase ${ }^{2}$, evitando o acento frasal.

Foram coletadas 1.152 palavras através da leitura de frases que constam no Anexo A. Esta tarefa foi aplicada a oito informantes: quatro falantes nativos do Brasil, todas mulheres; e quatro nativos da Espanha, grupo composto por um homem e três mulheres. Os participantes tinham entre 26 e 31 anos no momento das gravações e todos haviam concluído pelo menos o Ensino Médio. Uma vez coletados os dados, realizou-se uma análise acústica com o Programa Computacional PRAAT. Cada uma das palavras-alvo tem entre 3 e 5 sílabas, e as sílabas-alvo estão marcadas em negrito no Anexo A. Todas as sílabas analisadas para este experimento são sílabas abertas e apresentam a mesma estrutura silábica, sendo todas compostas por uma consoante seguida por monotongo. As sílabas alocadas em posição inicial e final de palavra foram evitadas; e as medições são sempre tomadas a partir de sílabas em posição média de palavra. Avaliaram-se quatro diferentes tipos de sílabas ("ma”, "na", "ni” e "rì") em situações átonas e tônicas. Como é possível observar, duas das sílabas-alvo são compostas por vogal alta, e outras duas, por vogal baixa, o que possibilita verificar se a qualidade do segmento influencia de alguma forma o comportamento sistemático da duração silábica na expressão da proeminência lexical.

\subsection{Resultados}

Os resultados apresentados a seguir são referentes à média aritmética da duração de cada um dos quatro tipos de sílaba avaliados neste estudo. Os valores das sílabas compostas pelos mesmos segmentos foram agrupados

${ }^{2}$ Ver Anexo A. 
individualmente por sujeito (P1, P2, P3 e P4 para os sujeitos falantes de Português; e S1, S2, S3 e S4 para os falantes de Espanhol). Todos os valores são plotados em duas categorias diferentes: presença ou ausência de proeminência acentual ${ }^{3}$.

O Gráfico 1 está subdividido em círculos e quadrados e em ícones brancos e pretos. Os ícones brancos representam as sílabas átonas, enquanto os pretos representam as sílabas tônicas. Os quadrados correspondem aos dados obtidos de falantes de PB, e os círculos ilustram os valores coletados com falantes espanhóis.

Gráfico 1 - Média aritmética da duração para PB e Espanhol em sílabas tônicas e átonas

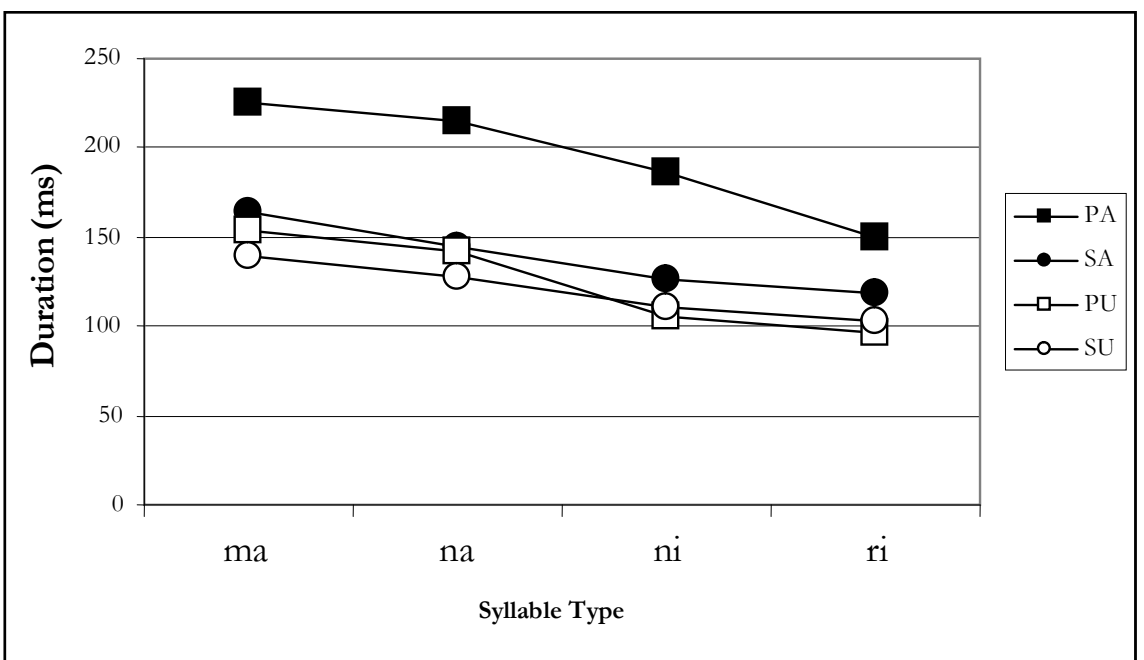

Fonte: Ferreira, 2008.

O Gráfico 1 mostra que os valores de duração obtidos, tanto com sílabas em posição tônica como com sílabas em posição átona de palavra em Espanhol, são próximos aos valores de duração de sílabas átonas em PB. O gráfico mostra que os valores médios de duração das sílabas acentuadas em

${ }^{3}$ Para maiores detalhes sobre os dados, consultar Ferreira (2008). 
Português são muito mais elevados do que os valores relativos a todas as outras três medições. Estes resultados indicam que, em situações átonas, a duração das sílabas em PB e em Espanhol é semelhante, porém, o acento de palavra em PB favorece um grande acréscimo na duração das sílabas. Se, para calcular como se comporta a duração diante da presença do acento de palavra, forem consideradas como base as sílabas átonas, é possível computar o quanto aumenta a duração de uma sílaba ao receber a proeminência acentual. O Gráfico 2 nos mostra percentualmente esse aumento na duração.

Gráfico 2 - Percentagem de aumento na duração silábica para PB e Espanhol. Valores referentes aos sujeitos agrupados segundo a língua e o tipo silábico

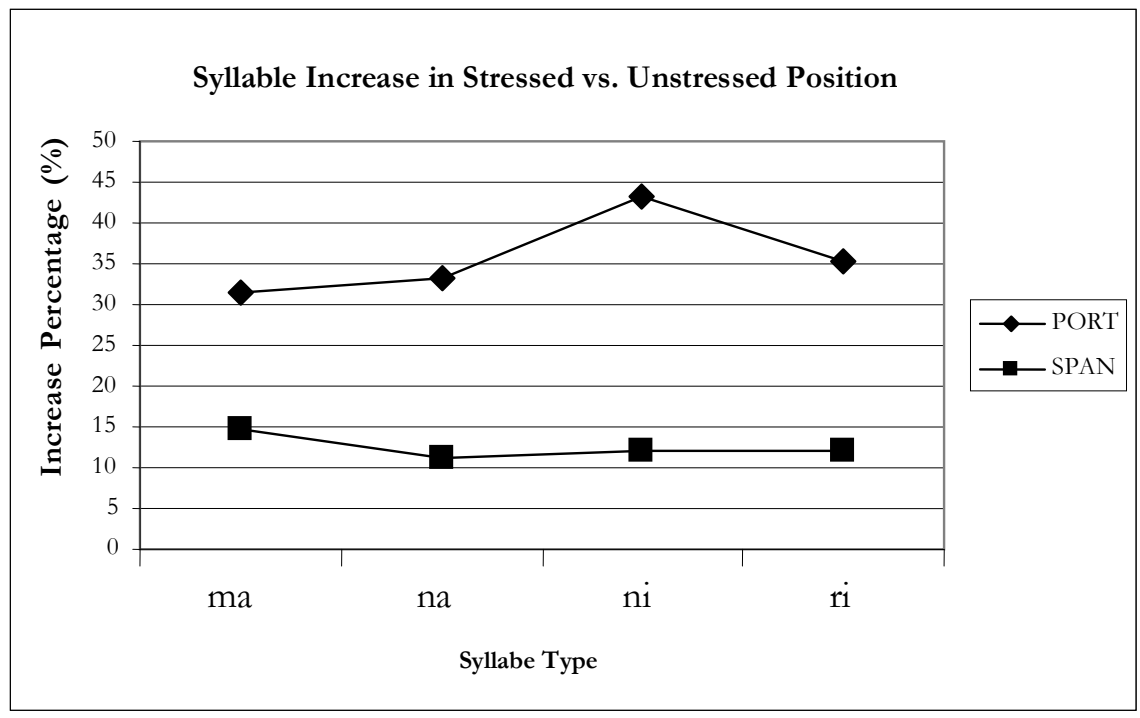

Fonte: Ferreira, 2008.

No Gráfico 2, os resultados obtidos com todos os falantes de uma mesma língua foram plotados juntos, respeitando a separação entre os quatro diferentes tipos de sílaba. A imagem mostra o percentual de acréscimo na duração das sílabas acentuadas com relação às não acentuadas. No Gráfico 2, notou-se que, no PB, a duração das sílabas acentuadas compostas por vogais altas tendem a aumentar mais do que a duração das compostas por vogais baixas. Isto indica que o tipo de segmento determina o comportamento da 
duração silábica, exigindo um maior ou menor índice de duração para expressar a proeminência lexical. Quanto ao Espanhol, verificou-se que, quando acentuada, a sílaba "ma" tende a apresentar maior aumento na duração do que as demais sílabas da mesma língua, indicando mais uma vez a possibilidade da qualidade dos segmentos influir na maneira sistemática como a duração opera para atingir a meta de comunicar o acento de palavra. Uma vez que os resultados plotados acima estão baseados em uma média aritmética de todos os sujeitos falantes de uma mesma língua, faz-se necessário observar o comportamento individual de cada falante para verificar essa tendência. $\mathrm{O}$ Gráfico 3 mostra a medição individual do acréscimo na duração para cada um dos oito sujeitos que participaram do experimento, indicando que, no PB, o aumento médio na duração de uma sílaba, quando acentuada, é de $25 \%$ a 45\%. Estes valores são bem mais baixos para o Espanhol: a comparação das médias obtidas para cada sujeito mostra que as sílabas tônicas normalmente duram em torno de $0 \%$ a $22 \%$ a mais que as átonas.

Gráfico 3 - Percentagem do aumento na duração silábica em PB e Espanhol plotada individualmente para os quatro sujeitos de cada língua

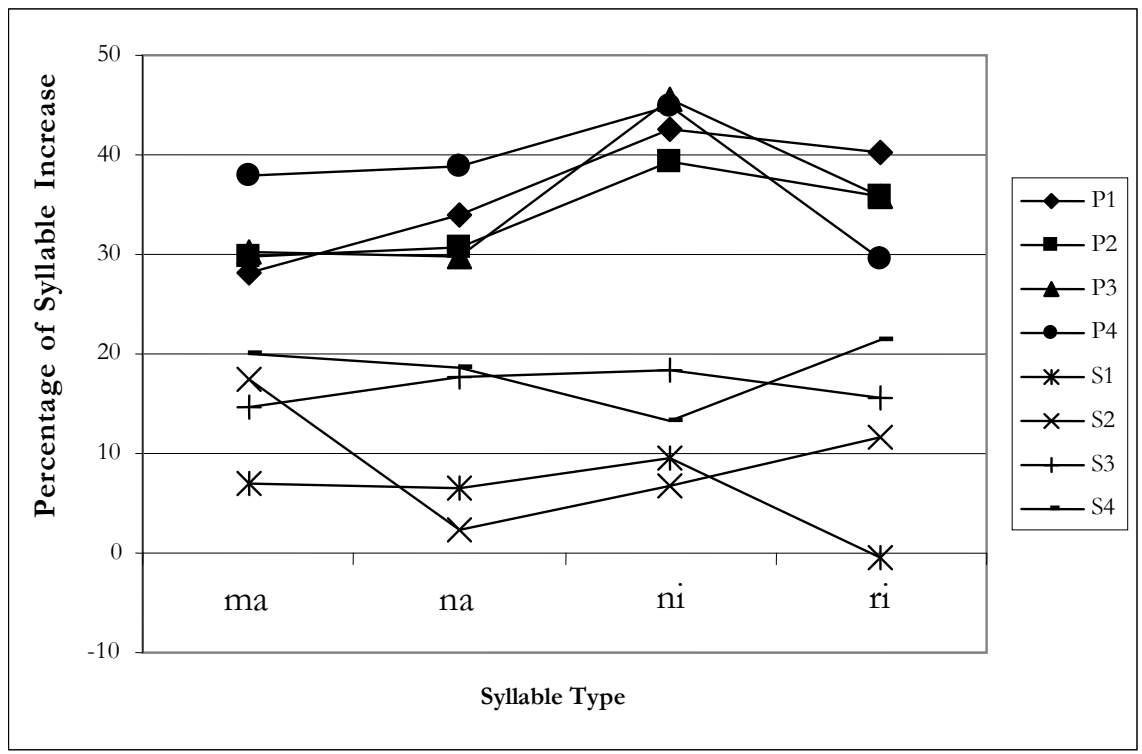

Fonte: Ferreira, 2008. 
Ao comparar os Gráficos 2 e 3, fica claro que, enquanto há um comportamento consistente e firme por parte dos falantes de PB no que diz respeito ao aumento da duração silábica em posição acentuada de palavra, os falantes do Espanhol apresentam muita variação individual. A consistência no aumento da duração silábica no PB parece estar diretamente relacionada tanto com a qualidade da vogal quanto com a da consoante, pois nota-se um percentual de aumento específico para cada tipo de sílaba. Os dados mostram que a duração não funciona de forma tão marcada ou sistemática no Espanhol, pois, além de apresentar um percentual menor de aumento nas tônicas, o comportamento da duração da sílaba parece ser determinado principalmente pelo estilo pessoal do sujeito e não pelos segmentos silábicos. De forma geral, a tendência apresentada pelo aumento da duração no PB é consistente e sistemática, tanto no que diz respeito aos sujeitos quanto no tocante ao tipo de segmento que compõe a sílaba. No Espanhol, os dados mostram grande variação no comportamento dos falantes. Nota-se que o percentual de aumento na duração silábica em Espanhol não parece estar relacionado com a qualidade da vogal ou mesmo com a qualidade da consoante.

Os resultados indicam que, embora o aumento na duração esteja significativamente associado às sílabas acentuadas em ambas as línguas, o mecanismo operante que regula as características quantitativas da duração silábica e que reflete o acento lexical difere consideravelmente. É notável o comportamento mais uniforme e robusto por parte do Português, tanto com relação à variação entre sujeitos quanto com relação às características intrínsecas aos segmentos.

Ao agrupar todas as médias e submetê-las a uma análise de variância (ANOVA- Two Way) replicada, com o alfa fixado em 0,05, chegou-se aos resultados do Quadro 1. 
Quadro 1 - ANOVA- Two Way replicada

\begin{tabular}{|c|c|c|c|c|}
\hline $\begin{array}{c}\text { Tipo de } \\
\text { sílaba }\end{array}$ & $\begin{array}{c}\text { Fonte de } \\
\text { Variação }\end{array}$ & $F$ & Valor de $P$ & F crítico \\
\hline \multirow{3}{*}{ "ma" } & Línguas & 14,41488 & 0,002545 & 4,747221 \\
\hline & Tipo de acento & 23,82086 & 0,000378 & 4,747221 \\
\hline & Interação & 5,747043 & 0,033684 & 4,747221 \\
\hline & $\begin{array}{l}\text { Fonte de } \\
\text { Variação }\end{array}$ & $F$ & Valor de $P$ & F crítico \\
\hline \multirow{3}{*}{ "na” } & Línguas & 13,92966 & 0,002862 & 4,747221 \\
\hline & Tipo de acento & 15,32546 & 0,002054 & 4,747221 \\
\hline & Interação & 5,798244 & 0,033036 & 4,747221 \\
\hline & $\begin{array}{l}\text { Fonte de } \\
\text { Variação }\end{array}$ & $F$ & Valor de $P$ & F crítico \\
\hline \multirow{3}{*}{ "ni" } & Línguas & 14,34709 & 0,002587 & 4,747221 \\
\hline & Tipo de acento & 44,99736 & 0,0000217 & 4,747221 \\
\hline & Interação & 20.51049 & 0,000691 & 4,747221 \\
\hline & $\begin{array}{c}\text { Fonte de } \\
\text { Variação }\end{array}$ & $F$ & Valor de $P$ & F crítico \\
\hline \multirow{3}{*}{ "ri" } & Línguas & 3,816093 & 0,074474 & 4,747221 \\
\hline & Tipo de acento & 28,41505 & 0,000179 & 4,747221 \\
\hline & Interação & 8,771142 & 0,011885 & 4,747221 \\
\hline
\end{tabular}

A análise de variância mostra que todos os valores de p com relação ao "Tipo de acento" do Quadro 1 são muito menores que 0,05, e que seus F críticos são sempre inferiores aos respectivos valores de F. Isso se traduz como uma diferença muito significativa entre sílabas tônicas e átonas em todos os tipos de sílabas contidas no corpus. O valor de F para "Línguas" é consistentemente mais alto do que seu respectivo valor de F crítico para cada sílaba, exceto por "ri". Esses resultados indicam que existe uma importante diferença no comportamento da duração silábica entre os idiomas em questão. Não se pode, porém, ignorar o fato de que o valor crítico F da sílaba "ri”" é maior do que o valor de $\mathrm{F}$, e, como consequência, o valor de p é superior a 0,05 para esse tipo de sílaba. Estes dois valores elevados indicam que a duração do "ri" nos dados coletados com os falantes de PB tem uma duração similar aos coletados com a mesma sílaba em Espanhol. A explicação para esse resultado pode ser, pelo menos de forma parcial, o fato de que o segmento 
/r/ é intrinsecamente breve. Estudos futuros sobre o tema são necessários para confirmar essa hipótese. Porém, é possível observar desde já que esse resultado reforça mais uma vez a teoria de que o tipo de segmento determina o comportamento da duração silábica em PB.

Vale ressaltar, ainda, que os valores de p para "Interação" entre o tipo de idioma e o tipo de acento são menores do que 0,05 no tocante a todas as sílabas em estudo. Isto indica que existe uma interação significativa entre os diferentes idiomas analisados neste estudo e os diferentes tipos de acento, sugerindo que, em geral, a duração se comporta de forma específica para cada tipo de acento segundo o idioma analisado.

\subsection{Discussão dos resultados}

Os resultados do experimento mostram que os falantes de PB apresentam um padrão de comportamento claro no que diz respeito à duração das sílabas tônicas em contraste com as sílabas átonas. Em termos percentuais, as sílabas no PB tendem a aumentar entre 29\% e 45\% quando acentuadas. Além disso, a qualidade do segmento parece influenciar o comportamento da duração silábica, uma vez que o tipo de segmento determina a percentagem de aumento de duração da sílaba que recebe proeminência.

Por outro lado, os dados do Espanhol não dão qualquer indicação de que a qualidade do segmento desempenhe um papel importante ao comparar a diferença entre a duração de sílabas tônicas e átonas. Sem apresentar um comportamento uniforme, os dados do Espanhol sugerem um forte caso de variação entre sujeitos. Isso indica que cada falante desenvolve uma maneira individual e sistemática de organizar a duração no seu próprio discurso diante do propósito de comunicar a proeminência lexical. A análise de variância de fatores (ANOVA- Two way replicada) foi feita e sugere que os resultados obtidos no estudo são altamente significativos.

Em suma, quando acentuadas, as sílabas em PB tendem a aumentar em uma percentagem média muito maior e com muito menos variação entre falantes que em Espanhol. Portanto, pode-se concluir que a duração silábica como correlato acústico do acento lexical funciona de forma muito mais robusta e confiável para expressar proeminência em PB do que em Espanhol. É importante observar, ainda, que os resultados apresentados refletem o contexto e os tipos de segmento avaliados no experimento. A posição da sílaba dentro da palavra em questão - assim como a presença de pausas, ênfases, acentos de frase, entre outros fenômenos linguísticos - afetará o 
comportamento da duração silábica (MASSINI, 1992; MASIPI, 1999; BARBOSA, 2002; ORTEGA-LLEBARIA; PRIETO, 2007, entre outros).

\section{Implicações para o Material Didático}

Apesar da evidência de que o uso adequado dos aspectos suprassegmentais da língua pode melhorar a inteligibilidade, como discutido na seção 2, o ensino de suprassegmentais não é priorizado em muitos programas de língua, nem na produção de material didático comercial (CHELA-FLORES, 2003). Para além da postura individual que cada professor de língua pode adotar em sala de aula quanto ao ensino da pronunciação, sabe-se que um dos grandes desafios, tanto para a implementação do ensino de suprassegmentais na sala de aula, como para o preparo de material didático referente ao tópico, tem origem na falta de informação específica sobre as diferenças entre línguas. Primeiro, é necessário que se conheça em detalhes o funcionamento exato de um sistema ou do contraste entre sistemas para poder ensiná-lo de forma precisa.

Com ênfase na linguística contrastiva, o presente trabalho provê informação específica sobre o funcionamento de algumas características acústicas do Espanhol e do Português que têm implicação para os suprassegmentais. A partir do mapeamento das diferenças entre as línguas, foi possível observar que, quando relacionada à expressão do acento de palavra, a duração silábica no PB opera de forma bem mais aguda e sistemática do que no Espanhol. A compreensão destas características funciona como instrumentação fundamental para que se possa desenvolver material didático específico e, por consequência, mais funcional para alunos nativos de uma das línguas durante o aprendizado da outra.

É necessário que se pergunte ainda como fazer uso destas informações para promover melhor aproveitamento das mesmas por parte de professores e alunos. O que se sabe sobre as diferenças entre as duas línguas deve ser utilizado no material didático de forma implícita ou explícita ${ }^{4}$ ?

${ }^{4}$ Para Ellis et al. (2008), a aprendizagem implícita ocorre através de operações não conscientes e consiste na aquisição de conhecimentos através de um estímulo complexo, mas é um processo que ocorre naturalmente. Já a aprendizagem explícita se constitui de uma operação consciente, na qual, através de estímulos e testes de hipóteses, o indivíduo busca uma determinada estrutura. 
Alguns teóricos do ensino de línguas estrangeiras já chegaram a argumentar que o ensino de elementos explícitos da L2 não induz à aquisição (KRASHEN, 1981). Contudo, existem pesquisas que se posicionam em direção oposta, indicando que o conhecimento explícito sobre o comportamento da língua estrangeira a ser aprendida também pode contribuir para a melhora no desempenho linguístico dos alunos. Estudos nos quais as variáveis foram controladas mostram que a instrução com foco na forma referente à fonologia pode contribuir para um melhor desempenho de alunos de língua estrangeira. Esses estudos mostram, também, que o conhecimento fonológico explícito está relacionado a diferenças de caráter positivo no que toca à compreensão da fala (GIAMBO; MCKINNEY, 2004; VENKATAGIRI; LEVIS, 2007). A literatura mais recente sugere que a associação entre o significado e a forma através da generalização de esquemas e de memorização nos permite forjar o conhecimento de forma implícita, mas vários outros aspectos do conhecimento de uma segunda língua só se dão de forma explícita; e, embora ambos os tipos sejam distintos e separados, eles interagem entre si na construção do conhecimento geral (ELLIS et al., 2009; SANZ; LEOW, 2011).

Tendo em vista que ambos os tipos de conhecimento podem auxiliar o aprendizado, potencializando o desempenho dos alunos, sugere-se que as atividades propostas para o ensino de suprassegmentais estejam voltadas para o desenvolvimento do conhecimento explícito e do implícito. Com o propósito de exemplificar a preparação e utilização de material didático para o ensino das características linguísticas suprassegmentais, será apresentada, na subseção 3.1, uma sequência de atividades adaptadas para abordar o funcionamento da duração com base nos resultados obtido no experimento acima descrito. O material que segue simula atividades que poderiam estar incluídas em livros didáticos de língua estrangeira, acompanhados de CD.

\subsection{Descrição e exemplo de material didático}

Em um primeiro momento, a apresentação de atividades compostas por material autêntico e que contenha exemplos salientes do contraste entre sílabas tônicas e átonas na língua-alvo pode ajudar a sensibilizar os alunos quanto ao funcionamento do sistema da L2. Por estimular operações não conscientes, esse tipo de atividade ajuda na construção do conhecimento implícito, e é auxiliada pelo processo natural de repetição. Esse tipo de exercício está exemplificado na atividade 1 , que pode tanto ser utilizada em sala de aula, quanto de forma autônoma pelos alunos. 
Em um momento posterior, pode-se, ainda, sugerir que o professor teste a habilidade dos alunos em reconhecer a diferença entre sua língua materna e a L2. Na atividade 2, a apresentação de áudio com palavras idênticas pronunciadas por falantes de ambos os idiomas pede que o aluno selecione quais das formas refletem a língua estrangeira e quais se encontram no idioma nativo. Com a aplicação desse tipo de atividade em sala de aula, o professor pode solicitar que os alunos expliquem o porquê de suas respostas. Esse tipo de atividade instiga a curiosidade e provoca o reconhecimento da estrutura linguística, abrindo portas para atividades de cunho mais explícito - como o detalhamento de mais diferenças entre as línguas por parte do professor. Maiores detalhes sobre a distinção entre línguas também podem estar contidos no material didático e podem ser explorados em atividades como a 3 e a 4 . $\mathrm{Na}$ atividade 3 , sugere-se a combinação de material áudio ${ }^{5}$ e visual, para facilitar o mapeamento de ideias, e na atividade 4, é proposta uma estratégia de indução e constatação de fatos através de perguntas. Seguem exemplos de como estruturar tal sequência de atividades no corpo do material didático:

1. Escute e, em seguida, repita as palavras abaixo.

a) moribundo

b) camarada

c) vinícola

d) narigudo

e) manada

f) animal

g) verídico

h) bonito

i) marido

j) finito

k) dirigente

l) único

${ }^{5}$ Em material didático comercial, o áudio estaria contido no CD que acompanha o livro. As figuras utilizadas na atividade 3 foram obtidas através de Praat (BOERSMA; WEENINK, 2013). 
2. Na sequência, você ouvirá as palavras abaixo produzidas tanto por falantes de Espanhol como por falantes de Português. Após ouvir cada palavra, indique se a palavra foi pronunciada em Português ou Espanhol e explique o porquê de sua decisão.
a) semana
b) lírica
c) tomate
d) serenata
e) banana

3. Observe os espectrogramas e compare os números escritos abaixo de cada sílaba. Eles refletem a duração da vogal $a$ em cada uma das sílabas da palavra "banana". Que generalizações sobre o Português e o Espanhol você pode encontrar comparando as figuras?

a) Português

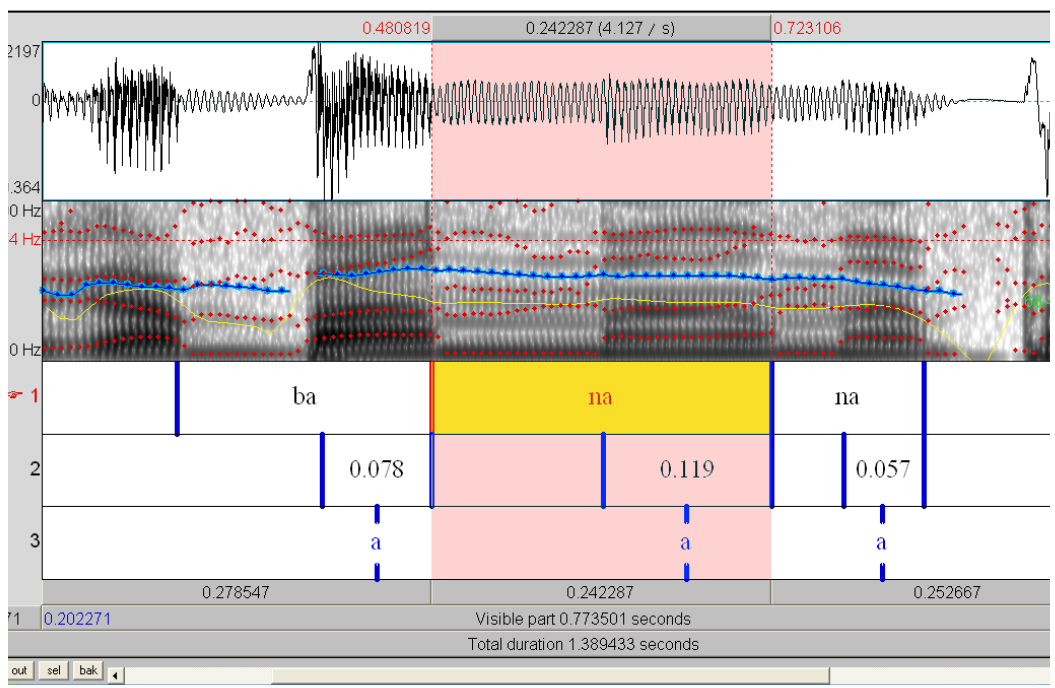


b) Espanhol

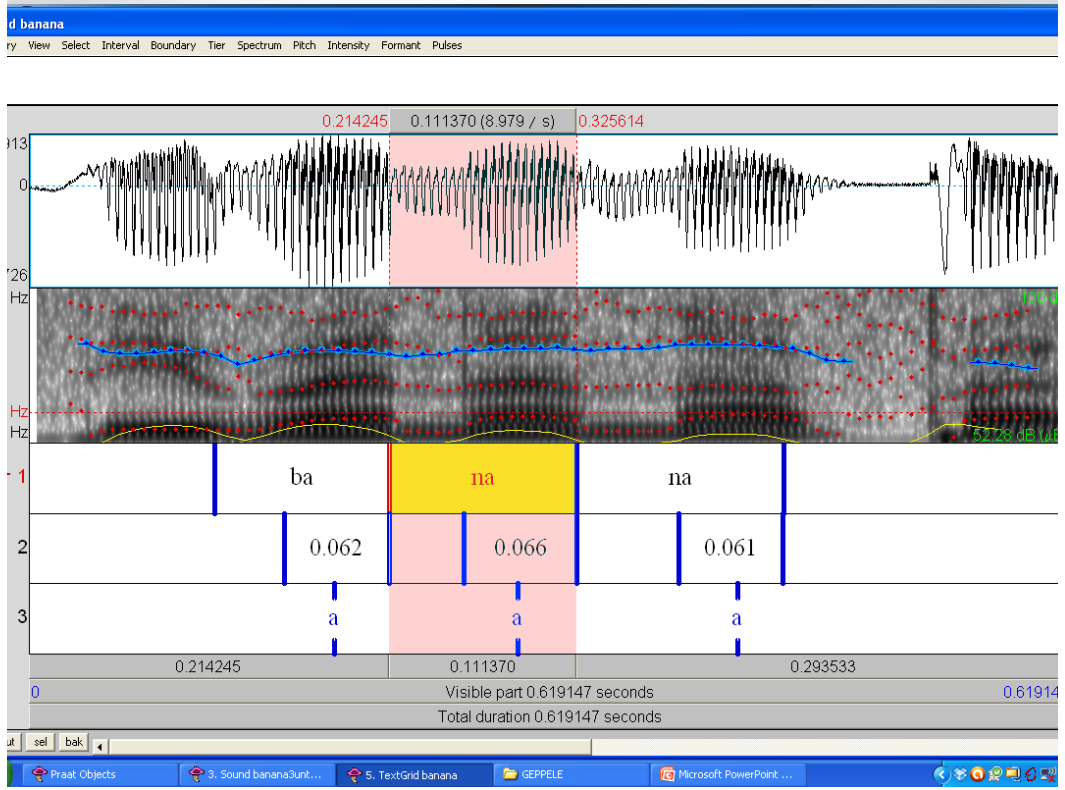

4. Volte às figuras acima e responda as perguntas que seguem:

a) O que acontece com a duração da vogal em posição tônica em ambas as línguas?

b) Em qual das duas línguas a duração da vogal tende a variar mais?

c) Compare as vogais átonas em posição inicial e final de palavra. Qual a relação entre a duração da pré-tônica e da pós-tônica no Português? Essa relação também se reflete no Espanhol?

Os exemplos dados nas quatro atividades acima permitem que o aluno possa, de forma autônoma, praticar o conhecimento implícito e explícito de como opera a língua-alvo e começar a reconhecer o contraste entre línguas. Essas atividades podem servir, ainda, como gancho, abrindo portas para que os professores possam comentar como funcionam os aspectos que influenciam a compreensão do acento lexical e do ritmo em ambas as línguas. O professor 
pode fazer várias observações, como, por exemplo, mencionar que a mesma vogal se comportará de maneira diferente em uma língua, dependendo da sua proeminência acentual. O professor pode, também, destacar que as sílabas tônicas no Português tendem a ser muito mais longas que as átonas, o que ocorre no Espanhol com menor intensidade. Pode discorrer sobre o fato de as pré-tônicas normalmente serem tão longas quanto às pós-tônicas na língua espanhola, mas que o $\mathrm{PB}$ apresenta tendência à redução silábica em posição final de palavra. O conhecimento dessas características, entre outras, permitiria uma discussão mais profunda sobre a percepção do acento de palavra e do ritmo nessas línguas. É óbvio que, para que o professor possa discutir tais assuntos com profundidade, se espera que ele tenha noções básicas sobre a acústica da produção de fala. Daí se destaca a relevância e a aplicação prática das noções de acústica, que têm ganhado espaço nos currículos de fonética e fonologia dos cursos de Letras de diversas universidades no país.

Entende-se que a preparação de material didático requer tempo; por isso, se defende a ideia de que a inserção desse tipo de atividade em materiais didáticos comerciais é altamente relevante e necessária. Além de fornecer instrumentos importantes para a abordagem das características suprassegmentais em sala de aula, a presença desse tipo de sequência no material didático comercial é um lembrete para o professor sobre a importância de abordar tais tópicos com os alunos. Essa adição facilita a discussão do tema e poupa tempo e trabalho ao professor de língua.

\section{Conclusão}

Os resultados apresentados no presente estudo são de grande relevância na tarefa de elaboração de material didático específico para falantes de Português aprendendo Espanhol, e vice-versa. A melhor compreensão de como opera a duração, característica prosódica que rege as relações de expressão do acento lexical e ritmo nesses idiomas (FERREIRA, 2008; FROTA; VIGÁRIO, 2000, entre outros), é fundamental para alunos e professores que trabalham com ambas as línguas. Estudos futuros devem aprofundar-se no tema e abordar as implicações da duração para as diferenças de ritmo entre essas línguas. A inclusão dessas informações específicas no material didático pode trazer maior ênfase ao ensino de suprassegmentais, fortalecendo o processo de ensino-aprendizagem de línguas estrangeiras. Conclui-se, portanto, que é necessário incentivar o aprendizado de 
suprassegmentais, tanto através da disponibilização de informação explícita sobre as diferentes características dessas línguas, quanto através da inclusão, no material didático, de atividades e exercícios que incentivem a prática e o conhecimento implícito destas características.

\section{Agradecimentos}

Sinceros agradecimentos a José Ignácio Hualde, Stella Telles, Daniel Thornhill, Vicente Masip, Luísa Lima e a dois revisores anônimos, pelos comentários e sugestões. Todos os erros e imperfeições desse artigo são, obviamente, de nossa responsabilidade. Agradecimentos especiais a FACEPE e ao CNPq pela bolsa de pesquisa que possibilitou a constituição desse trabalho.

\section{Anexo}

Anexo A - Corpus usado para a coleta de dados

Corpus Português

01) Diga anatoMIa para mim. ${ }^{6}$

02) Diga LÍrico para mim.

03) Diga aNIta para mim.

04) Diga anaGRAma para mim.

05) Diga poMAda para mim.

06) Diga toMAte para mim.

07) Diga seMAna para mim.

08) Diga MÉrito para mim.

09) Diga anaNÁS para mim.

10) Diga CÍnico para mim.

${ }^{6}$ As sílabas tônicas estão representadas em letras maiúsculas e as sílabas-alvo estão destacadas em negrito para que os leitores possam identificá-las mais facilmente. Quando a lista de frases foi apresentada aos sujeitos, para leitura, não havia nenhum tipo de destaque nas palavras e os sujeitos não podiam diferenciar visualmente as sílabas tônicas nem as sílabas-alvo das demais sílabas. 
11) Diga caNIno para mim.

12) Diga piRÔmano para mim.

13) Diga chaMAda para mim.

14) Diga senhoRIta para mim.

15) Diga baNAna para mim.

16) Diga FÔnico para mim.

17) Diga caMAda para mim.

18) Diga diNÂmica para mim.

19) Diga animaÇÃO para mim.

20) Diga semiNÁrio para mim.

21) Diga moriBUNdo para mim.

22) Diga NÔmade para mim.

23) Diga camaRAda para mim.

24) Diga viNÍcola para mim.

25) Diga nariGUdo para mim.

26) Diga maNAda para mim.

27) Diga aniMAL para mim.

28) Diga veRÍdico para mim.

29) Diga boNIto para mim.

30) Diga governaDOR para mim.

31) Diga fiNIto para mim.

32) Diga diriGENte para mim.

33) Diga Único para mim.

34) Diga maRIdo para mim.

35) Diga camale ̃̃O para mim.

36) Diga Árido para mim.

37) Diga peRIto para mim.

38) Diga minaREte para mim.

39) Diga domaDOR para mim.

40) Diga sereNAta para mim.

41) Diga analoGIA para mim.

42) Diga jorNAda para mim.

43) Diga caRÍcia para mim.

44) Diga feRIda para mim.

45) Diga carNívoro para mim.

46) Diga aniMAda para mim. 
Corpus Espanhol

01) Di anatoMía para mí.

02) Di Lírico para mí.

03) Di aNIta para mí.

04) Di anaGRAma para mí.

05) Di poMAda para mí.

06) Di toMAte para mí.

07) Di seMAna para mí.

08) Di MÉrito para mí.

09) Di anaNÁS para mí.

10) Di CÍnico para mí.

11) Di caNIno para mí.

12) Di piRÓmano para mí.

13) Di llaMAda para mí.

14) Di señoRIta para mí.

15) Di baNAna para mí.

16) Di FÓnico para mí.

17) Di caMAda para mí.

18) Di diNÁmica para mí.

19) Di animaCIÓN para mí.

20) Di semiNArio para mí.

21) Di moriBUNdo para mí.

22) Di NÓmada para mí.

23) Di camaRAda para mí.

24) Di viNícola para mí.

25) Di nariGUdo para mí.

26) Di maNAda para mí.

27) Di aniMAL para mí.

28) Di veRÍdico para mí.

29) Di boNIto para mí.

30) Di gobernaDOR para mí.

31) Di fiNIto para mí.

32) Di diriGENte para mí.

33) Di Único para mí.

34) Di maRIdo para mí.

35) Di camaleÓN para mí. 
36) Di Árido para mí.

37) Di peRIto para mí.

38) Di minaREte para mí.

39) Di domaDOR para mí.

40) Di sereNAta para mí.

41) Di analoGía para mí.

42) Di jorNAda para mí.

43) Di caRIcia para mí.

44) Di heRIda para mí.

45) Di carNívoro para mí.

46) Di aniMAda para mí.

\section{Referências}

AKERBERGUE, M. Aquisição da pronúncia: a entoação em afirmações e perguntas sim/não. Trabalhos de Linguística Aplicada, Campinas, v. 50, n. 1, p. 153-167, 2011.

BARBOSA, P. At least two macrorhythmic units are necessary for modeling Brazilian Portuguese duration. In: ESCA TUTORIAL RESEARCH WORKSHOP ON SPEECH PRODUCTION MODELING AND FOURTH SPEECH PRODUCTION SEMINAR, 1., 1996, Autrans. Proceedings.... Autrans, 1996. p. 85-88.

BARBOSA, P. Explaining Brazilian Portuguese resistance to stress shift with a coupled-oscillator model of speech rhythm production. Cadernos de Estudos Linguisticos, v. 43, p. 71-92, 2002.

BOERSMA, P.; WEENINK, D. Praat: doing phonetics by computer [Computer program]. Version 5.3.56. Disponível em: <http://www.praat.org/>. Acesso em: 9 set. 2013.

CÂMARA, J. The Portuguese Language. Chicago: University of Chicago Press, 1972.

CARMOLINGA, R. A distância da proximidade. A dificuldade de aprender uma língua fácil. Intercâmbio, São Paulo, v. 6, 1997. Disponível em: 
<http://www2.lael.pucsp.br/ tony/intercambio_anteriores / 06index.htm>. Acesso em: 20 jun. 2014.

CARVALHO, A. M. Português para falantes de espanhol: perspectivas de um campo de pesquisa. Hispania, v. 85, p. 597-608, 2002.

CHELA-FLORES, B. Optimizing the teaching of english suprasegmentals. Barcelona English Language and Literature studies, Barcelona, v. 12, 2003.

Disponível em: <http://www.publicacions.ub.edu/revistes/bells12/>. Acesso em: 10 out. 2013.

CONTERAS, M. As armadillas que podem ser oferecidas pela proximidade dos idiomas - a interlíngua oferecida como insumo nas aulas de Língua Espanhola como LE. 1998. Dissertação (Mestrado em Letras) Universidade Católica de Pelotas, Pelotas.

DERWING, T.; MUNRO, M. Second language accent and pronunciation teaching: A research-based approach. Tesol Quartely, v. 23, p. 379-398, 2005.

ELLIS, R.; LOEWEN, S.; ELDER, C.; ERLAM, R. Implicit and explicit knowledge in second language learning, testing and teaching. Buffalo: Multilingual Matters, 2008.

ESLING, J. H.; WONG, R. F. Voice quality settings and the teaching of pronunciation. TESOL Quarterly, v. 17, p. 89-95, 1983.

FERREIRA, L. High initial tones and plateaux in Spanish and Brazilian Portuguese neutral declaratives: Consequences to the relevance of F0, duration and vowel quality as stress correlates. 2008. Tese (Doutorado em Linguística) - University of Illinois at Urbana-Champaign, Urbana.

FIALHO, V. R. Proximidade entre linguas: algumas considerações sobre a aquisição do espanhol por falantes nativos de Português Brasileiro. 2006. Disponível em: <http://pendientedemigracion.ucm.es/info/especulo/ numero31/falantes.html>. Acesso em: 23 set. 2013.

FROTA, S.; VIGÁRIO, M. Aspectos de prosódia comparada: ritmo e entoção no PE e no BP. In: ENCONTRO DA ASSOCIAÇÃO PORTUGUESA DE LINGUÍSTICA, 15., 2000, Braga. Actas... Braga, 2000. p. 533-555. 
GIAMBO, D.; MCKINNEY, J. The effects of a phonological awareness intervention on the oral English proficiency of Spanish - speaking kindergarten children. TESOL Quarterly, v. 38, p. 95-117, 2004.

GILAKJANI, A. The significance of pronunciation on English language teaching. English Language Teaching, v. 5, p. 96-107, 2012.

GILI GAYA, S. Elementos de fonética general. Madrid: Gredos, 1971.

GROSJEAN, F.; LI, P. The psycholinguistics of bilingualism. Malden: WileyBlackwell, 2013.

HAHN, L. D. Primary stress and intelligibility: Research to motivate the teaching of suprasegmentals. TESOL Quarterly, v. 38, p. 201-223, 2004.

KRASHEN, S. Second language acquisition and second language learning. Oxford: Pergamon, 1981.

MAJOR, R. Stress and rhythm in Brazilian Portuguese. In: KOIKE, D. A.; MACEDO, D. P. (Orgs.). Romance Linguistics: The Portuguese Context. Westport, Connecticut; London: Bergin Garvey, 1992 [1985]. p. 3-30.

MASIPI, V. Curso de fonología y ortografía españolas para brasileños. Barcelona: Difusión, 1999.

MASSINI, G. Acento e ritmo. São Paulo: Contexto, 1992.

NAVARRO TOMÁS, T. Manual de pronunciación española. Madrid: Hernando, 1926 [1914].

NICKEL, G.; WAGNER, K. H. Contrastive linguistics and language teaching. In: JORDENS, P.; ROBERTS, L. (Orgs.) International Review of Applied Linguistics in Language Teaching. Berlin: De Gruyter Mouton, 2009. p. 233-256.

ORTEGA, L. Understanding second language acquisition. London: Hodder Education, 2009.

ORTEGA-LLEBARIA, M. Phonetic cues to stress and accent in Spanish. In: DÍAZ-CAMPOS, M. (Org.). Selected proceedings of the 2 nd conference of laboratory approaches to Spanish Phonology. Somerville: Cascadilla Press, 2006. p. 104-118. 
ORTEGA-LLEBARIA, M.; PRIETO, P. Disentangling stress from accent in Spanish: production patterns of the stress contrast in deaccented syllables. In: PRIETO, P.; MASCARÓ, J; SOLÉ, M. J. (Orgs.). Segmental and prosodic issues in romance phonology. Amsterdam; Philadelphia: John Benjamins, 2007. p. 155-175.

ORTEGA-LLEBARIA, M.; HONG, G.; FAN, Y. English speakers' perception of Spanish lexical stress: Context-driven L2 stress perception. Journal of Phonetics, v. 41, p. 186-197, 2013.

QUILIS, A. Tratado de fonología e fonética españolas. Madrid: Gredos, 1993.

SANZ, C.; LEOW, R. Implicit and explicit language learning: Conditions, processes, and knowledge in SLA and bilingualism. Georgetown:

University Press, 2011.

SELINKER, L. Interlanguage. In: JORDENS, P.; ROBERTS, L. (Orgs.) International review of applied linguistics in language teaching. Berlin: De Gruyter Mouton, 2009. p. 209-232.

VENKATAGIRI, H.; LEVIS, J. Metaphonological knowledge and comprehensibility: An exploratory study. Language Awareness, v. 16, p. 263-277, 2007.

Recebido em: 31/01/2014 Aceito em: 13/05/2014 